\title{
Análise do Arcabouço Legal do Controle Congressual Sobre o Banco Central do Brasil
}

\author{
Adalberto Felinto da Cruz Júnior \\ José Matias-Pereira
}

\begin{abstract}
RESUMO
O presente trabalho teve como objetivo principal analisar o arcabouço legal à disposição do Congresso Nacional para o controle e supervisão das burocracias públicas federais, com o intuito de contribuir para o aprimoramento dos controles sobre essas agências estatais, tendo em vista o contexto de aprofundamento da vivência democrática, ora experimentado no Brasil. Para tanto, utilizou-se especificamente o caso do Banco Central do Brasil e procedeu-se a avaliações nos mecanismos de governança legalmente instituídos sobre o Bacen, em vigor até outubro de 2003. A partir da análise pôde-se concluir que o processo de delegação e, conseqüentemente, a estrutura de governança e de tomada de contas por parte do Congresso são incompletos, na medida em que a autoridade supervisora do Bacen se mostra mais efetivamente exercida pelo Poder Executivo que, em última instância, detém os poderes efetivos relacionados ao controle e supervisão sobre aquela entidade pública, em detrimento do Poder Legislativo. O controle parlamentar apresenta-se, assim, limitado, irresoluto e frequientemente restrito a circunstâncias de apreciação de decisões já tomadas, fragilmente vinculado com as etapas de formulação e implementação das políticas relacionadas à moeda, ao crédito e ao câmbio.
\end{abstract}

Palavras-chave: teoria da agência; enfoque principal-agente; controle congressual; burocracia; Banco Central do Brasil.

\begin{abstract}
Given the context of consolidation of the democratic experience in Brazil, this research seeks to analyze the role of the Brazilian National Congress in controlling and supervising the federal bureaucracies, aiming to contribute to the improvement of the control over federal agencies. In order to accomplish the documental research, it has been used the case of the Brazilian Central Bank (Bacen). The research has been carried out by investigating the legal governance mechanisms created over the Bacen which are represented by the existing legislation at October/2003. It has been concluded that the delegation process and, consequently, the dynamics of accountability in use by the National Congress seem to be flawed. This can be attributed to the fact that the oversight authority over Bacen is effectively practiced by the Executive, which is the ultimate owner of the power over that public entity. Thus, the legislative control becomes more complex and usually limited to circumstances under which decisions are already taken, as it has not been previously linked with the stages of formulation and implementation of the monetary policy.
\end{abstract}

Key words: agency theory; principal-agent approach; congressional oversight; bureaucracy; Brazilian Central Bank. 


\section{INTRODUÇÃO}

Os Estados contemporâneos estão cada vez mais pressionados a oferecer a seus cidadãos uma crescente e variada gama de serviços. Para tanto estão tendo de expandir seu aparato burocrático, a fim de se aparelharem para responder às crescentes demandas da sociedade. Contudo, "para evitar o problema de alto grau de autonomia ou ausência de controle por parte das agências públicas, os políticos eleitos devem querer e poder controlar as burocracias que não estão sujeitas à sanção popular direta" (Loureiro, 2001, p. 49).

Assim, surge a necessidade de se criar mecanismos de responsabilização das burocracias que as tornem mais eficientes e ao mesmo tempo responsáveis, evitando-se tanto as ameaças advindas da autonomia exagerada, quanto as decorrentes de sua captura por interesses privados. Mecanismos de responsabilização, nesse sentido, são os instrumentos de controle recíproco dos poderes por meio dos quais o Legislativo, o Judiciário e diversas agências estatais, fiscalizam os governantes de forma continuada e não apenas episódica, como nos períodos de eleição.

No Brasil, os poderes Legislativo e Judiciário têm demonstrado débil capacidade de exercer contrapeso sobre o poder Executivo, o qual tem exercido demasiada autoridade sobre a condução das agências públicas, sem muito se preocupar com a prestação de contas e transparência de seus atos.

Ademais, para Loureiro e Abrucio (1999), o caráter multipartidário do presidencialismo brasileiro faz com que a administração pública possa se constituir em moeda de troca nas negociações de cargos públicos. Assim, pelo padrão de interação do Executivo e Legislativo, ancorado na construção de coalizões majoritárias de apoio e sustentação ao Presidente da República, reduzse a capacidade de efetivo controle das agências burocráticas por parte do Parlamento.

No caso das autarquias responsáveis pela condução dos assuntos econômicos e financeiros do governo, a fragilidade do controle e da supervisão congressual intensifica-se. Por serem responsáveis por áreas extremamente sensíveis da administração pública, essas organizações insularam-se dos controles externos e tornaram-se verdadeiros enclaves dentro do aparato estatal, impermeáveis à influência dos outros poderes constituídos, que não o Executivo. Esse insulamento, se por um lado as tornou imunes a possíveis influências indevidas por parte dos políticos, por outro transformou-as em órgãos não sujeitos à necessidade 
democrática de prestação de contas e responsabilização (Loureiro \& Abrucio, 1999).

Exemplo ilustrativo dessa situação de insulamento é o Banco Central do Brasil - BACEN, autarquia criada no bojo das reformas encetadas pela revolução de 1964 e responsável pela administração da política monetária e cambial do governo federal. Desde sua criação contou com considerável distanciamento da influência do controle legislativo; apenas recentemente, com o restabelecimento da democracia, vem tendo sua atuação avaliada pelos congressistas, que têm discutido melhores formas de acompanhar suas decisões e de estabelecer mecanismos de responsabilização de seus dirigentes. Sobre o assunto, Santos e Patrício (2002) declaram que "devido ao impacto das decisões desta agência específica sobre a vida dos brasileiros, o sistema político não poderia deixar de colocar na agenda a questão do controle das ações, muitas vezes discricionárias, de seus dirigentes".

Assim, em face da reconhecida limitação de controle das agências públicas por parte do legislativo, propôs-se a seguinte questão de pesquisa: Como são estruturadas as prerrogativas de controle do Congresso Nacional sobre o Banco Central do Brasil?

Como objetivo central deste trabalho, teve-se a intenção de qualificar o arcabouço legal instituído pelo Congresso Nacional Brasileiro, para o controle e a supervisão do Banco Central do Brasil, a partir da caracterização dos instrumentos de supervisão congressual utilizados sobre aquela autarquia; da qualificação da relações de governança entre o Legislativo e a autoridade monetária; e da avaliação do processo de prestação de contas do Banco Central do Brasil perante o Congresso Nacional.

O presente trabalho organizou-se de forma que, nesta primeira parte, foi apresentado o tema da pesquisa, evidenciando o problema estudado e os objetivos perseguidos. Na segunda e terceira parte, foi elaborado o marco teórico, a partir do qual se desenvolveu o trabalho, buscando-se evidenciar os principais conceitos relacionados ao controle legislativo, tanto sobre a burocracia pública em geral, quanto sobre o Banco Central em particular. Na quarta parte, foi descrita a metodologia da pesquisa, definindo e especificando os procedimentos metodológicos adotados, o método e a natureza do estudo, as categorias de análise e as fontes utilizadas para a pesquisa. Na quinta parte, foram apresentados os resultados da pesquisa, em que estão expostos os dados coletados e desenvolvida a análise dessas informações, perseguindo o esquema definido na metodologia. E na sexta parte, é feita a exposição das conclusões e das considerações finais. 


\section{Controle Legislativo sobre a Burocracia}

Para McCubbins, Noll e Weingast (1987), a premissa fundamental da modelagem do controle congressual sobre a burocracia é que os burocratas têm preferências pessoais em conflito com as dos membros do congresso. E, se de um lado, as escolhas dos políticos sempre são submetidas à ratificação dos eleitores via voto, de outro as escolhas das agências públicas não são objeto da disciplina eleitoral. Conseqüentemente, na falta de um controle efetivo, as escolhas burocráticas podem refletir as preferências pessoais derivadas da combinação entre valores políticos privados, objetivos de carreira pessoal e aversão ao esforço, especialmente esforços que não revertam em benefícios pessoais.

Assim, como consequiência da delegação de autoridade para os burocratas é que eles podem tornar-se mais experts sobre as políticas sob sua responsabilidade do que os representantes eleitos, sendo possível, para eles, obter vantagens das informações a que têm acesso, como em toda a relação de agência. Daí surge a questão de como os políticos eleitos podem, de forma razoavelmente efetiva, assegurar que suas intenções serão perseguidas. O problema do controle legislativo da burocracia configura-se, então, como típico problema de principal-agente, no qual as organizações públicas podem extrapolar de seus limites, não atuando de acordo com as preferências dos políticos.

Ainda para os autores acima citados, porque o monitoramento e a supervisão não são livres de custo, nenhum método de governança administrativa será perfeito. Os representantes eleitos defrontam-se, assim, com um trade-off entre a extensão da aderência que eles podem comandar e o esforço despendido para assegurar essa aderência, esforço este que tem um custo de oportunidade, porque também poderia ser usado para outros propósitos políticos relevantes.

Para McCubbins e Shwartz (1984), o congresso exerce suas atribuições de controle por meio de dois tipos de técnicas de supervisão congressual, a saber:

- supervisão tipo patrulha de polícia: análoga ao uso das patrulhas de polícia, é centralizada, ativa e direta, dependendo da iniciativa do congresso para ser deflagrada. Nela o congresso examina uma amostra de agências com a finalidade de detectar e remediar qualquer violação dos objetivos legislativos, desencorajando as transgressões. As agências são supervisionadas de diversas maneiras, tais como leitura de documentos, observações de campo e audiências para questionar os responsáveis ou cidadãos afetados;

. supervisão tipo alarme de incêndio, análoga ao uso do alarme de incêndio real; esse tipo de supervisão é menos centralizada, envolve menos atividades e 
intervenções diretas. Ao invés de examinar uma amostra de decisões administrativas, procurando violações dos objetivos legislativos, o congresso estabelece um sistema de papéis, procedimentos e práticas informais que habilitam os cidadãos, individualmente ou em grupos organizados, a examinar as decisões das organizações e certificar se houve violações dos objetivos congressuais. O papel do congresso consiste em criar e aperfeiçoar esse sistema descentralizado e, ocasionalmente, intervir em resposta às reclamações.

Segundo McCubbins et al. (1987), os mecanismos de supervisão clássicos, do tipo monitoramento, recompensa e punição, podem servir para submeter os burocratas recalcitrantes à humilhação pública, o que devasta suas carreiras. Embora essas ações sejam reativas, pelo fato de se darem após a ocorrência de alguma impropriedade, o que as caracteriza como controles ex-post, o valor da punição multiplicado pela possibilidade de o comportamento impróprio ser detectado e punido entra no cálculo do custo do benefício líquido do burocrata que, eventualmente, pretenda afastar-se das orientações políticas. Caso a detecção e punição sejam suficientemente prováveis e a magnitude da punição suficientemente grande, a ação imprópria pode ser detida. Assim, a presença das sanções provê algum tipo de proteção contra inadequações, ao forçar os administradores a antecipar a reação dos políticos sobre suas decisões.

Contudo, ainda para aqueles autores, por eles próprios, recompensas e punições não tratam diretamente com o problema da informação assimétrica. Se as agências têm melhor informação, elas têm espaço discricionário não detectável pela supervisão política; assim, na ausência de monitoramento, algumas decisões inadequadas não serão objeto de punição. $\mathrm{O}$ sistema de recompensas e sanções também não é uma solução completamente efetiva para o problema de controle, porque pode impor custos igualmente aos atores políticos, porquanto, além dos recursos alocados no monitoramento terem custo de oportunidade, os métodos de impô-lo podem gerar desgastes para os políticos, já que os cidadãos podem ser levados a ter dúvidas sobre o desempenho dos eleitos e concluírem que são eles (os políticos) e não as agências que estão divergindo dos interesses públicos. Além do mais, o ato de impor sanções distrai a atenção das agências do seu principal objetivo, qual seja, oferecer serviços públicos, focando suas energias em minimizar os estragos de possíveis inadequações. Claro que se a imposição de sanções é onerosa tanto para os atores políticos quanto para os burocratas, o ardor para aplicá-las será proporcionalmente amenizado. Especificamente, nem todos os atos inadequados detectados serão punidos significativamente, o que dará às agências incentivos adicionais para perseguir suas próprias preferências às custas dos políticos. Dessa forma, monitoramento e sanções não representam uma solução perfeita para o problema da adequação burocrática, porque são onerosos, inexatos e sujeitos a limitações fundamentais. 
Para McCubbins et al. (1987), outra forma de solucionar o problema de indução dos burocratas à convergência para os interesses públicos é por meio do estabelecimento de procedimentos administrativos, conhecidos como controles ex-ante. Essa modalidade de supervisão provê os meios de induzir à aderência burocrática, não requerendo tempo, esforço e recursos dos atores políticos, habilitando-os a resolver os problemas de controle das agências. O estabelecimento de procedimentos administrativos soluciona os problemas de assimetria de informações, ao dar meios para suprir as desvantagens informacionais. Estruturando os procedimentos das agências, suas atividades ficam estabelecidas de tal forma que há regulação das informações coletadas e disseminadas, limitando-se as opções de escolha e a definição de estratégias. Caso a utilização dos procedimentos administrativos seja efetiva, a agência, sem necessidade de qualquer intervenção, direcionamento ou atuação especial dos atores políticos, é levada em direção às decisões que os políticos teriam tomado eles próprios. Por isso o estabelecimento de procedimentos administrativos adequados constitui-se em mecanismo adicional para garantir a aderência das agências burocráticas, amenizando os problemas de informação assimétrica e reduzindo os custos dos métodos de monitoramento e punição. Os procedimentos administrativos podem ser usados para guiar as agências na tomada de decisões que sejam proximamente consistentes com as preferências políticas.

Mitnick (1980) notou que os agentes públicos podem ser motivados pelo interesse público ou por seus próprios interesses, implicando que os reguladores devem continuamente policiar a aderência da ação dos agentes ao interesse público. Contudo esse acompanhamento não é isento de custo, o que faz com que, na relação entre políticos e burucratas, o principal, ou seja os políticos, movido racionalmente, visando a maximizar sua utilidade, somente supervisione o que espera que lhe proporcione retorno. Além disso, tendo em vista a racionalidade limitada e os custos de informação, os critérios de retorno para o interesse público são muito difíceis de medir. Assim, no relacionamento entre principal (políticos) e agente (burocracias públicas), inevitavelmente, existe uma perda de controle.

Os custos de monitoração e a possibilidade de o principal decidir não monitorar o comportamento dos agentes, segundo citado autor, explica por que os interesses públicos podem ser submetidos aos interesses privados. Esse fato faz surgir uma diferença importante entre o modelo principal-agente aplicado ao setor privado e o aplicado ao setor público. No modelo aplicado ao setor público, se o principal decide não exercer o monitoramento do agente, nenhum dos dois assume custo adicional pela decisão ou pela ação indevida do agente. O custo é de fato assumido pela sociedade, que é o principal dos políticos. Os legisladores assumirão custos, somente se, pela falta de supervisão, o público tiver conhecimento da ocorrência 
de escândalos. Circunstância que não ocorre na aplicação do modelo principalagente ao setor privado.

Assim é que, levando em consideração as especificidades das relações de agência que envolvem os políticos e as burocracia, Mitnick (1980) desenvolveu, com base no arcabouço conceitual da teoria da agência, um modelo institucional ou regulatório do controle burocrático, e examinou o relacionamento entre os agentes da burocracia e seus principais, ou seja, os políticos. Dessa forma, construiu uma tipologia dessas relações de agência geradas a partir das seguintes dimensões:

nível de condescendência/consentimento entre principal e agente a partir da ação dos agentes;

. a fonte/origem das especificações das ações dos agentes; e

. o nível de discricionariedade atribuída ao agente pelo principal.

\section{Controle Legislativo sobre o Banco Central do Brasil}

O controle exercido pelo congresso sobre os órgãos governamentais é influenciado pelos interesses dos congressistas que estão centrados na maximização de suas preferências e utilidades. Dependendo de seus objetivos, uma determinada estrutura de controle será construída e um tipo específico de supervisão será exercido. No caso brasileiro, especificamente, a par das preferências dos legisladores, deve-se também levar em conta, para a análise das estruturas de governança sobre a burocracia, a forma pela qual o Congresso Nacional se insere na estrutura política do Estado, principalmente no que se refere aos pesos específicos de que dispõe com relação aos outros atores institucionais. Como o modelo da inter-relação do Executivo e Legislativo no Brasil se dá nos termos do presidencialismo de coalizão, que consiste em complexo sistema de interações políticas entre membros do Executivo, burocratas, membros do Legislativo e líderes partidários, fica patente que as relações entre os poderes Executivo e Legislativo têm influência direta na prestação de contas das agências públicas, notadamente do Banco Central do Brasil. No assim chamado presidencialismo de coalizão, o presidente organiza sua base de sustentação política por meio da distribuição de postos na estrutura do Executivo e verbas orçamentárias aos partidos, e estes garantem os votos necessários à aprovação do programa de governo.

Para Amorim Neto e Tafner (2001), no caso brasileiro, de um ponto de vista formal, a burocracia estatal é agente de um único mandante - o Presidente da 
República - que, a partir da Constituição de 1988, passou a ter a prerrogativa de criar órgãos públicos e a iniciativa de propor projetos de lei relativos à administração pública (artigos 61 e 84 da Constituição Federal). Contudo a prerrogativa de fiscalizar as ações do Executivo é tarefa do Legislativo, sendo responsabilidade dos legisladores o controle das decisões dos membros das burocracias do Estado (artigos 49 e 70 da Constituição Federal). Assim, o funcionamento do presidencialismo de coalizão torna a ação fiscalizadora do Congresso objeto de negociação no seio das coalizões interpartidárias formadas para sustentar o governo.

Para Santos e Patrício (2002), a política monetária, por ser um tema complexo e estar envolvido em incertezas e riscos de impopularidade, trata-se de assunto que reúne fortes incentivos para que seja delegado a agentes públicos especializados. Contudo, na lógica de funcionamento do presidencialismo de coalizão experimentado no Brasil, se por um lado os legisladores possuem incentivos para delegar a política monetária ao governo, por outro possuem também incentivos para se diferenciarem de decisões consideradas impopulares e conquistarem apoio político por meio da atividade de fiscalização das ações do Banco Central consideradas indesejáveis ou inadequadas, havendo, portanto, uma tendência à construção de uma estrutura de controle do tipo ex-post, na qual as ações de supervisão são exercidas na medida que houver interesses para sua deflagração, desde que não haja prejuízo para a base de sustentação do governo.

Para os autores acima citados, a partir das circunstâncias das relações entre os poderes públicos brasileiros influenciadas que são por questões inerentes ao próprio funcionamento do sistema político mais amplo, o tipo de controle imposto ao Banco Central, além da dinâmica do relacionamento entre o Legislativo, o Executivo e o próprio Banco Central, depende também da capacidade de controle legislativo sobre as seguintes variáveis-chave da prestação de contas: a) os objetivos do banco central; b) o grau de transparência com que a diretoria do banco central toma decisões e desenvolve outras atividades; e c) responsabilidade final de seus dirigentes.

Aqueles autores asseveram que o grau de responsabilização dos bancos centrais perante o Legislativo será maior nas seguintes situações: quanto menos objetivos tiverem; quanto mais transparente for a tomada de decisões por meio da divulgação de relatórios, comunicados, atas de reuniões e comunicações aos dirigentes do Congresso; e quanto mais bem definida for a responsabilidade dos dirigentes em torno desses objetivos, com possibilidade de punições, incluindo a demissão. O resultado final da prestação de contas dependeria ainda dos pesos dados pelo Legislativo e pelo banco central aos objetivos, à transparência e à responsabilidade final dos dirigentes. 
Nesse sentido, Santos e Patrício (2002) ponderam que a partir da Constituição de 1988, a estrutura de prestação de contas do Banco Central é montada com ampla delegação de poder para as autoridades do Executivo, no sentido de definir a política monetária, paralelamente à definição de instâncias claras para que o Legislativo promova as atividades de tomada de contas.

\section{Aspectos Metodológicos da Pesquisa}

O modelo conceitual desta pesquisa utilizou basicamente três categorias de análise desenvolvidas a partir da abordagem teórica anteriormente descrita, quais sejam: a tipologia de controle congressual; as dimensões do modelo de principalagente do tipo institucional; e as variáveis-chave da prestação de contas para bancos centrais.

Na primeira categoria de análise apreciada - a tipologia do controle congressual — desenvolvida nos trabalhos de McCubbins e Schwartz (1984) e McCubbins et al. (1987), admite-se que a supervisão exercida pelo congresso sobre as burocracias públicas é moldada a partir da assunção do comportamento racional dos congressistas, da sua motivação por reeleições e da restrição de tempo e de conhecimento a que estão submetidos. Nesse contexto os procedimentos de controle podem ser agrupados em dois segmentos, e classificados como ex-ante ou ex-post.

Os controles ex-ante têm natureza preventiva e procuram interferir na configuração das organizações, instituindo estruturas e procedimentos que garantam que as ações das agências dar-se-ão de acordo com os interesses e orientações do legislativo. Esse tipo de controle busca organizar as agências de forma que elas prestem contas de seus atos e se limitem a agir nas fronteiras impostas pela autoridade legislativa. Já os controles do tipo ex-post têm natureza reativa e são utilizados para atestar, a posteriori, se as ações encetadas se deram de acordo com as orientações congressuais. Visam, portanto, punir ou recompensar as agências por atos já cometidos.

Os controles ex-post podem ainda ser desmembrados nos tipos patrulha de polícia ou alarme de incêndio. A supervisão tipo patrulha de polícia depende da iniciativa do congresso para ser deflagrada. Com ela o congresso examina uma amostra de agências com a finalidade de detectar e remediar qualquer violação dos objetivos legislativos, desencorajando as transgressões. Nesse tipo de supervisão as agências são inspecionadas de forma centralizada, ativa e direta. Já na supervisão tipo alarme de incêndio, ao invés de examinar uma amostra 
de decisões administrativas, procurando violações dos objetivos legislativos, o congresso estabelece um sistema de papéis, procedimentos e práticas informais que habilitam os cidadãos a examinar as decisões das organizações e certificar se houve violações dos interesses congressuais. O papel do congresso consiste em criar e aperfeiçoar esse sistema descentralizado e intervir em resposta às reclamações.

Na segunda categoria de análise utilizada — as dimensões de análise propostas por Mitnick (1980) para o modelo de principal-agente do tipo institucional — têmse: a) o nível de condescendência ofertado pelo principal ao agente, no presente caso representados pelo Congresso Nacional e Banco Central do Brasil, respectivamente; b) a origem das especificações para a atuação do agente, no caso Banco Central do Brasil; e c) o nível de discricionariedade do agente para implementar as ações a seu cargo.

Na primeira dimensão (nível de condescendência) levou-se em conta o grau de liberdade concedida pelo principal para atuação do agente. Analisou-se, assim, a margem de ação do agente permitida espontaneamente pelo principal e se suas ações precisam ou não ser constantemente submetidas à anuência superior. $\mathrm{Na}$ segunda dimensão (origem das especificações), trata-se das fontes de poder concedido pelo principal ao agente, levando-se em conta se o poder outorgado é originário de institutos formais (contratos, leis e prescrições) ou informais (tradição, costume ou aceitação tácita). Na terceira dimensão (nível de discricionariedade), trata-se das ações encetadas pelo agente, que são livres de condições impostas pelo principal. Leva-se em conta o espaço deixado à discrição do agente para sua atuação. $\mathrm{O}$ espaço discricionário pode tanto estar formalmente previsto ou originar-se de lacunas deixadas nos contratos estabelecidos formal ou informalmente.

A terceira categoria de análise utilizada refere-se às variáveis-chave de prestação de contas dos bancos centrais abordadas por Santos e Patrício (2002), quais sejam: a) os objetivos do banco central; b) o grau de transparência com que a diretoria do banco central toma decisões e desenvolve outras atividades; e c) a responsabilidade final de seus dirigentes.

A variável objetivos do banco central refere-se aos objetivos e metas atribuídas à instituição. A fim de garantir maior nível de prestação de contas e responsabilização da instituição, deve-se atribuir-lhe um número mínimo de objetivos, preferencialmente a função de garantir a estabilidade do poder de compra da moeda, ou seja, combater os desequilíbrios inflacionários. A variável grau de transparência tem relação com o modo pelo qual a direção do banco central toma suas decisões e como as submete à apreciação da sociedade. A transparência implica a comunicação ampla não só do resultado final da decisão, mas também 
da forma pela qual foi tomada e dos motivos que levaram a instituição a determinado posicionamento. Essa variável refere-se aos instrumentos de comunicação e visibilidade utilizados pela autoridade monetária em sua relação com outras instâncias. Já a variável responsabilidade final dos dirigentes têm relação com os incentivos negativos, ou seja, as punições utilizadas pelas autoridades supervisoras do banco central no caso de desempenho insatisfatório ou atuação indevida de seus diretores. Essa variável expressa os mecanismos de coerção à disposição dos controladores daquela autarquia, para que possam fazer valer efetivamente suas preferências. Também indica um limite de atuação da direção da organização que, em caso de descumprimento das orientações recebidas, fica sujeita à aplicação de penalidades.

O desenvolvimento deste trabalho deu-se por meio de pesquisa efetuada a partir do arcabouço normativo vigente até outubro de 2003, tendo sido analisadas as seguintes leis, decretos e normas: a Constituição Federal (CF) (art. 21; art. 22; art. 48; art. 49; art. 50; art. 52; art. 58; art. 61; art. 62; art. 70; art. 64; art. 84; art. 164; art. 192); a Lei $n^{\circ} 4.595$, de 31/12/64 que dispõe sobre a política e as instituições monetárias, bancárias e creditícias, cria o Conselho Monetário Nacional (CMN) e o Banco Central do Brasil (Bacen); a Lei no 9.069, de 29/06/1995 que dispõe sobre o Plano Real; o Decreto $n^{\circ} 3.088$, de 21/06/1999 que estabelece a sistemática de "metas de inflação"; a Lei Complementar no 101, de 04/05/2000 que estabelece normas de finanças públicas voltadas para a responsabilidade na gestão fiscal; e a Lei 10.524 (LDO), de 25/07/2002 que estabelece as diretrizes orçamentárias para o ano de 2003.

\section{Análise dos Dispositivos legais sobre a Governança do BaCEN}

A análise do disposto na Lei 4.595/64 e no art. 164 da CF, que tratam da criação do Banco Central - Bacen, do Conselho Monetário Nacional - CMN e da competência do Bacen para emissão de moeda, explicita uma clara e formalmente especificada delegação para o CMN e para o Bacen, tanto da autoridade de formular e implementar as políticas monetária, de crédito e cambial, quanto de normatizar e supervisionar o sistema financeiro nacional. Portanto há uma transferência das prerrogativas relacionadas à autoridade monetária para aquelas entidades. Note-se que ambas instituições (CMN e Bacen) situam-se no âmbito do Poder Executivo e lhes são concedidos amplos poderes, para em nome da União, direcionar os rumos das políticas relativas à moeda, ao crédito e ao câmbio, sem mencionar a necessidade de se envolver, a priori, o Poder Legislativo. Fica evidente ainda que na constituição dessas entidades, bem como na definição de suas responsabilidades e objetivos, não há previsão, pelo menos explícita, de 
prestação de contas perante outros poderes constituídos, principalmente o Congresso Nacional. Verifica-se assim a concessão de elevado nível de condescendência e discricionariedade a agentes, sem que sejam submetidos, $e x$ ante, a mecanismos de controle e supervisão que garantam ao Legislativo participação na definição das linhas mestras das políticas públicas de cunho monetário.

É de se reconhecer, portanto, que originariamente a autoridade monetária é delegada a agentes públicos não eleitos, que passam a contar com a condescendência dos políticos eleitos, principalmente legisladores, para atuar com considerável liberdade no âmbito de suas áreas de atuação. Frise-se que no artigo $4^{\circ}$, da Lei 4595 , é mencionado que a competência do CMN segue as diretrizes estabelecidas pelo Presidente da República, levando ao entendimento de que ao Congresso Nacional não é destinado papel de coordenação ex-ante no tocante a esses assuntos. Fica patente, por tanto, que o Poder Legislativo, sede da representação popular por excelência, não integra o núcleo de formulação das diretrizes econômicas relacionadas à moeda, tal como ocorre, por exemplo na formulação da política fiscal, em que o Congresso participa diretamente via discussão, aprovação e acompanhamento do orçamento da União.

Adicionalmente, observa-se que à autoridade monetária são destinados objetivos múltiplos: gestão da política monetária, cambial e de crédito, supervisão e regulamentação do sistema financeiro. Essa situação, segundo Santos e Patrício (2002), de profusão de objetivos, enfraquece o processo de prestação de contas e responsabilização, já que, além do fato de esses objetivos poderem ser concorrentes, a impossibilidade de se dedicar exclusivamente a uma meta, prioritariamente, pode caracterizar-se como atenuante para a ineficácia ou até mesmo acarretar a dispersão de esforços, gerando ineficiências. A prestação de contas fica, assim, prejudicada na medida em que a autarquia tem de dar satisfação sobre vários assuntos de natureza complexa, o que exige da autoridade supervisora a manipulação de muitos conhecimentos e informações técnicas, dificultando seu posicionamento e a determinação de parâmetros adequados de responsabilidade.

Outro aspecto que merece comentário é o fato de que em nenhum momento, nas diretrizes legais até aqui comentadas, há previsão de responsabilização clara para os agentes públicos delegados. Não são estabelecidos critérios objetivos de responsabilidade e punição para esses órgãos, caso não atuem de maneira adequada nos propósitos definidos pela própria lei.

Dos dispositivos constitucionais constantes nos artigos 21, 22 e 48 da CF, que tratam das competências da União e do Congresso Nacional, pode-se inferir quanto ao estabelecimento da necessidade de relação interativa entre o Poder Legislativo, o Poder Executivo e a autoridade monetária. Essa relação configura- 
se como uma espécie de controle do tipo ex-ante por regulamentar um procedimento relativo à definição da legislação sobre a moeda, o crédito, as finanças e o câmbio, estipulando que cabe ao Congresso dispor sobre as Leis que regulamentem esses assuntos. Ademais, concede ao Legislativo a atribuição de legislar sobre a criação de órgãos públicos, o que estabelece uma relação de principal-agente entre Congresso (principal) e burocracia (agente), já que o Legislativo participa da criação dos entes burocráticos. Contudo, apesar de estabelecer a competência do Legislativo para o trato de matérias relevantes para a União, os artigos em enfoque expressam claramente a necessidade da sanção do Presidente da República para tornar efetiva a legislação aprovada pelo Congresso.

Essa particularidade do procedimento legislativo brasileiro, ao mesmo tempo que estabelece o Poder Legislativo como ator do processo de regulação dos assuntos da União, concede ao Presidente da República status privilegiado e alto nível de poder discricionário em matérias legislativas, ao exigir a sanção presidencial para a efetivação das leis. Essa atribuição, que implica a possibilidade do exercício do poder de veto às disposições legislativas, na prática desequilibra a harmonia entre os poderes e confere ao Poder Executivo a possibilidade de obstar a implementação de normas que venham de encontro a seus interesses. Essa situação torna o Executivo um membro privilegiado do jogo de interação e barganha que caracteriza o processo legislativo, submetendo o Poder Legislativo a uma situação de constante negociação e sondagem das preferências presidenciais.

As orientações constitucionais contidas nos artigo 61, 62, 64, 66 e 84 da CF caracterizam o Presidente da República como ator privilegiado perante os órgãos burocráticos, incluindo o Banco Central, por determinar que, além de essas organizações ficarem sob sua subordinação administrativa, o que lhe permite dispor quanto a sua organização e funcionamento, a iniciativa das leis que estipulam a criação de agências governamentais, dentre outras, é de sua iniciativa privativa. Fica, dessa forma, evidenciado que na relação entre Poder Legislativo, Poder Executivo e Banco Central, há pelo menos dois principais, o Legislativo, por participar do processo de regulamentação das agências públicas, e o Presidente da República, a quem compete não só a iniciativa legislativa sobre o assunto, como também a direção superior da administração federal. O Presidente da República, portanto, pode ser considerado um principal privilegiado, por deter atribuições tanto executivas quanto legislativas, tornando seu relacionamento com os outros atores desvantajoso para os demais.

Outro aspecto a ser considerado é que, ao deter a iniciativa legislativa sobre assuntos da administração (art. 61 da CF), além da prerrogativa de poder solicitar urgência na tramitação de leis (art. 64 da CF), o Poder Executivo exerce o assim 
chamado poder de agenda, pelo fato de ser ele quem escolhe o adequado momento de se tratar dos assuntos de seu interesse, podendo assim escolher situações que lhe sejam mais favoráveis. A agenda legislativa fica, portanto, à mercê dos interesses do Executivo que, além de tudo, dispõe do poder de decreto, consubstanciado no instituto da medida provisória (art. 62 da CF). Essa figura constitucional confere ao Presidente da República o direito de legislar a priori do processo legislativo convencional, tornando a atuação congressual uma conseqüência de suas iniciativas.

Ademais, no caso do Bacen, é claramente estipulado (art. 84 da CF) que a nomeação de seu presidente é de competência privativa do Presidente da República, não havendo a estipulação de mandatos estáveis, o que torna o presidente do Banco Central demissível a partir da vontade do chefe do Poder Executivo.

Nas disposições constitucionais contidas nos artigos 49, 50, 52, 58 e 70 da CF, que tratam das atribuições e prerrogativas do Congresso Nacional, consagra-se o princípio da fiscalização congressual sobre o Poder Executivo, destinando-se ao Congresso a incumbência de fiscalizar os atos daquele Poder, pelo que se torna legítimo ao Legislativo tomar as contas das burocracias públicas, podendo, assim, interferir na condução dos negócios públicos, aí incluídos os assuntos relacionados à moeda. Deve-se ressaltar que as prerrogativas de controle do Congresso, ditadas na Constituição, caracterizam-se como mecanismos de supervisão do tipo ex-post, que se dão a posteriori da tomada de decisões e quando suas consequiências, na maioria das vezes, já estão consumadas.

Contudo a prática legislativa leva ao entendimento que esse tipo de controle é de relevante importância política para o Congresso, uma vez que só é deflagrado em vista de questões que venham ao encontro dos interesses dos congressistas e representem possibilidade de ganhos políticos. Nessa situação fica caracterizada a fiscalização do tipo alarme de incêndio em que a figura do fiscalizador só entra em ação quando soa algum alarme, no caso, a reclamação oriunda da sociedade.

Outra prerrogativa de controle legislativo refere-se à competência do Senado Federal de aprovar a escolha dos diretores do Banco Central, incluindo seu presidente (art. $52 \mathrm{da} \mathrm{CF}$ ). Esse poder, que deveria dotar o Senado de destacada importância em face da condução da política monetária por implicar que, pelo menos teoricamente, os indicados para conduzir o Bacen devam ter afinidades com as expectativas do Congresso, pode ser caracterizado como um tipo de controle ex-ante, por buscar garantir aderência da autoridade monetária ao Congresso previamente à tomada de decisões, implicando a presença de pessoas afinadas com o Legislativo dentre os dirigentes da organização. Contudo a prática 
não tem demonstrado esse significado, já que, estranhamente, todos os nomes submetidos pelo Executivo à apreciação congressual, para a direção do Bacen têm sido aprovados.

Os termos constitucionais constantes do art. $192 \mathrm{da} \mathrm{CF}$ postergam para momento ulterior o aprofundamento das definições sobre a organização do sistema financeiro nacional; contudo prevêem que a estruturação de suas instituições poderá dar-se por meio de múltiplas leis complementares, o que poderá facilitar o trâmite dessas matérias. Cabe frisar que antes das alterações promovidas pela EC 40/2003, de 29/05/2003, o artigo 192, originalmente, previa que a regulamentação do sistema financeiro se daria por meio de uma única lei complementar. Esse fato implicou, na prática, a impossibilidade de se regulamentar o assunto, já que o tema sistema financeiro é muito complexo e envolve vários outros subtemas além da estruturação do Banco Central, como o funcionamento e supervisão dos mercados de seguro, resseguro, previdência, capitalização, crédito e economia popular.

A Lei no 9069, de 29/06/1995, que instituiu o Real como unidade monetária do Brasil, também regulamentou a ação do Conselho Monetário Nacional, do Banco Central e criou, de forma objetiva, novos parâmetros de relacionamento com o Congresso Nacional, o qual passou a ter funções mais bem definidas no tocante ao processo de condução das políticas relacionadas à moeda. A entrada em vigor da aludida lei representou avanço no processo de prestação de contas do Bacen perante o Congresso Nacional, já que foram estipulados prazos para apresentação das metas de expansão monetária que estariam ancoradas no montante das reservas internacionais do país. Além disso previa-se a possibilidade de o Congresso rejeitar as programações monetárias propostas. Note-se que programação monetária e o quantitativo de moeda em circulação, bem como a relação da moeda nacional com a moeda norte-americana, o dólar, constituíam âncoras da política monetária, então em vigor, e davam as condições para a manutenção da estabilidade dos preços.

Contudo, do ponto de vista da participação congressual, é de se notar que o prazo para a apreciação das matérias, dada a complexidade do tema, era extremamente exíguo; somente dez dias $\left(\S 2^{\circ}\right.$ do art. $\left.6^{\circ}\right)$. E a prerrogativa de rejeição $\left(\S 3^{\circ}\right.$ do art. $\left.6^{\circ}\right)$, que poderia ser utilizada pelo Poder Legislativo, caso não concordasse com a proposta, só poderia ser adotada in totum, ou seja, o Congresso não poderia, a seu próprio juízo, estipular mudanças na programação monetária, cabendo-lhe, tão-somente, aprová-la ou rejeitá-la. Assim, a despeito da submissão do assunto à apreciação legislativa, o que se tinha, de fato, era uma consolidação da manutenção da autoridade monetária no âmbito do Poder Executivo, consagrando-se princípios já previstos na lei 4595. Dessa forma impôsse limites à ação do Congresso e, o que poderia constituir um mecanismo de 
controle eficaz, por se tratar da possibilidade de manifestação a priori da autoridade legislativa sobre o assunto, consolidando uma supervisão do tipo ex-ante, tornouse mais um rito formal a ser cumprido pelo Legislativo.

Por outro lado, a Lei 9.069 regulamentou procedimentos voltados para o aumento da transparência das decisões da diretoria do Bacen, ao determinar que o presidente da autarquia enviará periodicamente, tanto para autoridades executivas quanto legislativas, relatórios e demonstrativos sobre a programação monetária. Essa rotina enseja o estabelecimento de um controle do tipo ex-post, favorecendo o melhor acompanhamento da atuação da autoridade monetária.

Posteriormente, passados quatro anos de vigência da Lei 9069, as diretrizes da política monetária tiveram de ser novamente alteradas. O controle da expansão monetária deixou de prover os esteios necessários à manutenção da estabilidade econômica e, mesmo não revogando oficialmente as diretrizes estabelecidas pela citada lei, o governo por meio do Decreto Presidencial n 3088, de 21/06/1999, implementou o regime de metas de inflação.

A partir daí, constata-se que as prerrogativas anteriormente creditadas ao Congresso, quanto à aprovação das metas de expansão monetária, ficam obsoletas, já que o cerne da política monetária deixou de ser o controle dos agregados monetários e passou a ser a busca da convergência das expectativas inflacionárias do mercado em direção à meta de inflação estabelecida pelo governo. A fixação do novo regime reforça os poderes do Conselho Monetário Nacional, que fica responsável pela fixação das metas de inflação, mediante proposta do Ministro da Fazenda e confere ao Banco Central a competência de executar as políticas necessárias para o cumprimento dessa meta, não se atribuindo ao Congresso responsabilidades na formulação ou mesmo no controle da nova sistemática.

Não obstante essa limitação de controle, o decreto 3088 se ocupa de aspectos relacionados à transparência da autoridade monetária, porquanto, além de determinar a necessidade do Banco Central divulgar com periodicidade trimestral Relatório de Inflação, abordando tanto o desempenho do novo regime quanto o resultado de suas decisões, estabelece que, nos casos de descumprimento da meta inflacionária fixada, cabe ao Bacen divulgar publicamente as razões do seu não atingimento, por meio de carta aberta ao Ministro da Fazenda. Novamente estabelecem-se mecanismos de controle da autarquia por meio de procedimentos do tipo ex-post, ou seja, após a verificação da divergência, só que unicamente perante o Poder Executivo. Ao Congresso não cabe, formalmente, nenhum tipo de esclarecimento ou prestação de contas diretamente. Destaque-se ainda que não são previstos quaisquer tipos de sanções à autoridade monetária pela não consecução dos objetivos determinados, situação que reitera o baixo nível de 
responsabilização da agência pública perante os políticos eleitos, notadamente o Congresso Nacional.

A Lei de Responsabilidade Fiscal - LRF (LC 101, de 04/05/2000) instituiu diversas inovações no processo de prestação de contas e transparência do Banco Central, além de ter dado maior suporte às ações de supervisão do Congresso Nacional. Assim, ao estabelecer a necessidade de submeter anualmente ao Congresso, juntamente com a proposta de Lei de Diretrizes Orçamentárias LDO, na forma de anexo, os objetivos das políticas monetária, creditícia e cambial, as projeções para os principais agregados e variáveis, e as metas de inflação, estabelece-se um controle do tipo ex-ante, já que fica instituído um procedimento que dá oportunidade ao Congresso de conhecer antecipadamente a orientação que está sendo dada às políticas relacionadas à moeda, ao crédito e ao câmbio.

Outro instrumento de supervisão congressual, instituído pela LRF, é a estipulação da presença, duas vezes ao ano, do Banco Central perante as comissões temáticas do Congresso Nacional para avaliação do cumprimento dos objetivos e metas estipuladas, bem como para discussão do impacto fiscal das operações do Bacen. Essa medida, que institui uma sistemática de supervisão do tipo ex-post pode revelar-se eficaz na geração de convergência por expor os dirigentes do Bacen ao debate público e presumir deles embasamento e propriedade na tomada de decisões, que poderão ser objeto de questionamentos e até de contestação pelos legisladores.

É de se atentar, ainda, para o que dispõe a Lei de Diretrizes Orçamentárias (LDO) de 2002, ao fixar orientações para o exercício orçamentário de 2003, e estabelecer procedimentos a serem cumpridos pelo Banco Central. A LDO, ao prescrever a necessidade do envio trimestral de informações contábeis, balanços e balancetes, e de relatório prévio à reunião semestral prevista na LRF, estabelece um mecanismo de prestação de contas do tipo ex-post e submete o Bacen à necessidade de dispor suas contas com transparência, ensejando maior participação do Congresso na supervisão da autoridade monetária.

\section{Conclusões}

Da estrutura legal, ora analisada, transparece que a autoridade monetária é delegada ao Banco Central, o qual detém as prerrogativas de execução das políticas relacionadas à moeda, ao crédito, ao câmbio e à regulamentação e supervisão do sistema financeiro nacional. Fica patente também sua subordinação expressa e direta à diretrizes emanadas de autoridades executivas, 
quais sejam: o CMN (composto por dois ministros de Estado e pelo próprio presidente do Bacen) e o Presidente da República. Verifica-se, portanto, no que tange à supervisão do Bacen, uma clara predominância do Executivo, cabendo ao Legislativo um papel subsidiário quanto ao controle da autoridade monetária. O desequilíbrio de forças entre os Poderes Executivo e Legislativo agrava-se ainda mais, quando se leva em consideração as prerrogativas presidenciais relacionadas aos poderes de agenda, de veto e de decreto, o que implica a possibilidade de o Presidente da República interferir diretamente no processo legislativo, ora influenciando na determinação do calendário legislativo, ora obstando o fluxo da atividade congressual, ou ainda atuando diretamente na elaboração das normas legais.

Assim, as atribuições de controle legislativo resumem-se, muitas vezes, na aprovação dos dirigentes do Banco Central, indicados pelo Presidente da República, à promoção de audiências semestrais com o presidente do Bacen, a fim de discutir assuntos, principalmente, relacionados aos impactos fiscais das operações do Bacen, e à possibilidade de convocação de dirigentes para a prestação de esclarecimentos, quando for julgado necessário. Assim, via de regra, as competências legais de controle assumidas pelo Congresso priorizam dispositivos de supervisão ex-post, do tipo alarme de incêndio, o que implica que a ação legislativa se dá, geralmente, depois que as decisões já foram tomadas e suas consequiências, boas ou más, já estão assumidas. Dessa forma, a atuação congressual fica dependente da ocorrência de eventos negativos, para os quais seja necessária a intervenção do Congresso, por força da repercussão do caso junto à sociedade ou a grupos de interesse.

Os mecanismos de supervisão ex-ante previstos nas leis são de pouco alcance e estão geralmente relacionados a questões orçamentárias ou à aprovação da programação monetária que, por sinal, já não representa elemento de importância na dinâmica da condução da política monetária. Quanto à prerrogativa congressual de aprovar os nomes da diretoria do Bacen, é de se registrar que não está prevista nenhuma participação do Congresso no processo de afastamento da diretoria, que pode dar-se à discrição do Chefe do Executivo, deixando de se estabelecer, portanto, um vínculo maior entre o Legislativo e o Bacen.

Adicionalmente, a estrutura legal que estabelece a supervisão congressual sobre o Banco Central confere à autoridade monetária, em relação ao Poder Legislativo, alto nível de condescendência, relativa especificação formal de atribuições e elevado nível de discricionariedade. Alto nível de condescendência, porque o Bacen goza de considerável grau de liberdade, principalmente em face do Legislativo, para atuar sem ter de se ater a limites previamente estabelecidos, senão aqueles relativos às metas de inflação instituídos, exclusivamente, pelo Executivo. Relativa 
especificação formal de atribuições, porque, a despeito de que seus múltiplos objetivos estarem previstos em Lei, sua atual forma de atuação, orientada pelo regime de metas de inflação, não conta com a manifestação congressual. E elevada discricionariedade, porque as leis garantem ao Bacen amplo espaço de atuação, sem claro delineamento de seus limites, e com a possibilidade de poder definir sozinho, sem anuência do Legislativo, os procedimentos operacionais para alcançar as metas das políticas monetária e cambial.

A análise da estrutura regulamentar da supervisão congressual sobre o Bacen permite concluir, ainda, que é branda a capacidade de controle legislativo sobre as variáveis de prestação de contas da autoridade monetária, conforme se explicita a seguir.

- Os objetivos atribuídos ao Banco Central são múltiplos e estão relacionados a diversos assuntos, o que dificulta a efetiva supervisão do Congresso, porque confunde e torna dispersa a capacidade de responsabilização.

A transparência das decisões da diretoria do Bacen pode ser considerada satisfatória pelo elevado número de informações e relatórios periodicamente disponibilizados. Contudo, é de se ressaltar que o processo de tomada de decisão, quanto à administração do regime de metas de inflação, não está prescrito por norma congressual.

- A responsabilização dos dirigentes da autarquia monetária pode ser considerada fraca, pois não está prevista nenhuma forma de punição nos casos de não serem atingidos os objetivos, como também não estão especificadas medidas que possam constranger previamente seu comportamento, não cabendo ao Congresso nenhuma participação no processo de afastamento da diretoria do Banco.

Finalmente, por todo o exposto, pode-se concluir que o arcabouço de controle e supervisão e, conseqüentemente, o processo de tomada de contas do Banco Central, por parte do Congresso, são imperfeitos, na medida em que a autoridade supervisora do Bacen se mostra mais efetivamente exercida pelo Poder Executivo que, em última análise, detém os poderes e atribuições especificamente relacionados ao controle daquela entidade pública. Assim, o controle parlamentar apresenta-se limitado, irresoluto e freqüentemente restrito a circunstâncias de apreciação de decisões já tomadas, fragilmente vinculado às etapas de formulação e implementação das políticas relacionadas à moeda, ao crédito e ao câmbio, tornando frágil a efetiva atuação supervisora do Congresso Nacional.

\section{Artigo recebido em 12.08.2004. Aprovado em 27.10.2004.}




\section{ReferênCIAS Bibliográficas}

Amorim Neto, O., \&

Tafner, P. (2002, Abril).

Governos de coalizão e mecanismos de alarme de incêndio no controle legislativo das medidas provisórias. Dados, 45(1), 5-38.

Constituição da República Federativa do Brasil (2003).

Cláudio Brandão de Oliveira (Org.). (3a ed.). Rio de Janeiro: Roma Victor.

Decreto n 3.088 , de 21 de junho de 1999. Estabelece a sistemática de "metas de inflação" como diretriz para fixação do regime de política monetária e dá outras providências. Diário Oficial da União, Brasília, p. 4. Retificado no DOU, de 23/06/1999, p. 1.

Lei $\mathrm{n}^{\circ}$ 4.595, de 31 de dezembro de 1964 . Dispõe sobre a política e as instituições monetárias, bancárias e creditícias, cria o Conselho Monetário Nacional e dá outras providências. Diário Oficial da União, Brasília, p. 12081.

Lei n 9.069, de 29 de junho de 1995.

Dispõe sobre o Plano Real, o Sistema Monetário Nacional, estabelece as regras e condições de emissão do Real e os critérios para conversão das obrigações para o Real, e dá outras providências. Diário Oficial da União, Brasília, p. 9621.

Lei Complementar $\mathrm{n}^{\circ} .101$, de 04 de maio de 2000.

Estabelece normas de finanças públicas voltadas para a responsabilidade na gestão fiscal e dá outras providências. Diário Oficial da União, Brasília, 05/05/2000, seção 1, p. 1 .

Lei $n^{\circ}$. 10.524, de 25 de julho de 2002.

Dispõe sobre as diretrizes para a elaboração da lei orçamentária de 2003 e dá outras providências. Diário Oficial da União, Brasília, 26/07/2002, p. 1.

Loureiro, M. R. (2001).

O controle da burocracia no presidencialismo. In Cadernos Adenauer. Burocracia e Reforma do Estado (Vol. 3, pp. 47-72). São Paulo: Fundação Konrad Adenauer.

Loureiro, M. R., \&

Abrucio, F. L. (1999, outubro).

Política e burocracia no presidencialismo brasileiro: o papel do Ministério da Fazenda no primeiro governo Fernando Henrique Cardoso. Revista Brasileira de Ciências Sociais, 14(41), 68-89.

McCubbins, M., \&

Schwartz, T. (1984, February).

Congressional oversight overlooked: police patrols versus fire alarms. American Journal of Political Science, 28(1), 165-79.

McCubbins, M.,

Noll, R., \&

Weingast, B. R. (1987, Autumn).

Administrative procedures as instruments of political control. Journal of Law, Economics and Organization, 3(2), 234-277. 
Mitnick, B. M. (1980).

The political economy of regulation. New York: Columbia University Press.
Santos, F., \& Patricio, I. (2002, junho).

Moeda e poder Legislativo no Brasil: prestação de contas de bancos centrais no presidencialismo de coalizão. Revista Brasileira de Ciências Sociais, 17(49), 93-113. 
